\title{
Energy requirements during sponge cake baking: experimental and simulated approach.
}

(1)

\author{
M. Micaela Ureta ${ }^{\mathrm{a}}$, Sandro M. Goñi ${ }^{\mathrm{ab}}$, Viviana O. Salvadori ${ }^{\mathrm{ab}}$, Daniela F. Olivera ${ }^{\mathrm{a} 1}$

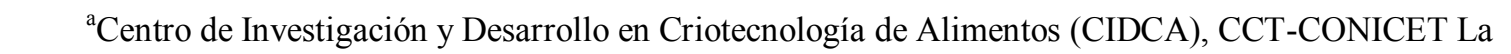 \\ Plata and Facultad de Ciencias Exactas, UNLP, 47 y 116, 1900 La Plata, Argentina \\ ${ }^{\mathrm{b}}$ Departamento de Ingeniería Química, Facultad de Ingeniería, UNLP, 115 y 48, 1900 La Plata, Argentina
}

Abstract

Baking is a high energy demanding process, which requires special attention in order to know and improve its efficiency. In this work, energy consumption associated to sponge cake baking is investigated. A wide range of operative conditions (two ovens, three convection modes, three oven temperatures) were compared. Experimental oven energy consumption was estimated taking into account the heating resistances power and a usage factor. Product energy demand was estimated from both experimental and modeling approaches considering sensible and latent heat. Oven energy consumption results showed that high oven temperature and forced convection mode favours energy savings. Regarding product energy demand, forced convection produced faster and higher weight loss inducing a higher energy demand. Besides, this parameter was satisfactorily estimated by the baking model applied, with an average error between experimental and simulated values in a range of 8.0 to $10.1 \%$. Finally, the energy efficiency results indicated that it increased linearly with the effective oven temperature and that the greatest efficiency corresponded to the forced convection mode.

Keywords: Baking, Energy demand, Efficiency, Sponge cake.

\footnotetext{
${ }^{1}$ Corresponding autor: daniela.olivera@conicet.gov.ar
} 
Cp Specific heat, $\mathrm{J} \mathrm{kg}^{-1}{ }^{\circ} \mathrm{C}^{-1}$

$f \quad$ Usage factor, dimensionless

$h_{c} \quad$ Effective heat transfer coefficient, $\mathrm{W} \mathrm{m}^{-2} \mathrm{C}^{-1}$

$k \quad$ Thermal conductivity, $\mathrm{W} \mathrm{m}^{-1} \mathrm{C}^{-1}$

$m \quad$ Product mass, kg

$N_{p} \quad$ Power, $\mathrm{W}$

$O E C$ Specific oven energy consumption, $\mathrm{kJ} \mathrm{kg}^{-1}$

$P E D \quad$ Specific product energy demand, $\mathrm{kJ} \mathrm{kg}^{-1}$

$r \quad$ Radius, $\mathrm{m}$

SEC Specific energy cost, $\$ \mathrm{~kg}^{-1}$

$t \quad$ Process time, $\mathrm{s}$ or $\mathrm{min}$

$T \quad$ Temperature, ${ }^{\circ} \mathrm{C}$

WL Weight loss, \%

$x \quad$ Mass fraction

Subscripts

$0 \quad$ Initial

app Apparent

ave Average

b Baking

eff Effective

$\exp \quad$ Experimental

fan Fan

heat Heating

$i \quad$ Component

lat Latent

oven Oven

sen Sensible

sim Simulated

water Evaporated

Greeks symbols

$\varepsilon \quad$ Average absolute relative error, \% 
$\rho \quad$ Global density, $\mathrm{kg} \mathrm{m}^{-3}$

$\lambda \quad$ Latent heat of vaporization of water at oven pressure, $\mathrm{J} \mathrm{kg}^{-1}$

$\eta \quad$ Efficiency of the baking process, \%

\section{Introduction}

27 During the last years energy costs have been rising significantly simultaneously with international legislation that forces manufacturers to reduce their carbon footprint in order to mitigate climate change fears. These factors are encouraging greater understanding of high-energy processes [1]. Particularly in the bakery industry, [2] discussed energy management systems, energy efficiency measures and the strategies to reduce energy consumption. Even though the study was based on USA bakery products its findings can be generalized to bakeries internationally. Authors identified four major

34 processes (fermentation, baking, cooling and freezing, and cleaning) that consume the vast majority of purchased energy. In this sense, the implementation of energy efficiency measures for these systems can reduce energy costs and lessen the impacts of volatile energy prices. Also, as bakery involves massive consumption products, there was developed specific technology in order to improve the efficiency of the process. To achieve this goal there has been of significant importance the research and innovation

40 focused on process efficiency with special concern on product quality [3].

41 Among all the stages involved in the bakery industry (ingredients selection, mixing, storage/dosing, baking, cooling, packing, storage, distribution and commercialization) the baking process itself is crucial. It is estimated that the energy demand during this 44 stage is in the range of $3-5 \mathrm{MJ} \mathrm{kg}^{-1}$.

45 The energy requirement of the baking process depends on two different aspects: the 46 energy needed to achieve the complete product transformation and the actual oven 47 energy consumption. The ratio between both values provides a direct and simple 
measure of the process energy efficiency [4]. Besides, the difference between the oven energy consumption and the product energy demand is the amount of energy absorbed by the oven trays and walls and the energy lost to the ambiance. Therefore, improving oven design and optimizing the process conditions (temperature, convective heat transfer and baking time) leads to energy savings; and for this purpose mathematical modeling of the baking process is a powerful tool.

54 Le Bail et al. [5] compared the energy consumption of two bread baking processes. Authors used a macroscopic approach that includes product and oven energy requirements to estimate an energy efficiency index which showed that part frozen baking had higher energy consumption than conventional baking. Alamir et al. [6] studied energy savings using jet impingement during French bread baking. Authors proposed a mechanistic heat and mass transfer model, which was able to estimate product energy demand and the potential energy savings. Paton et al. [7] analysed the energy requirements in a continuous industrial oven using a macroscopic balance and proposed a CFD scheme to study the influence of the operative conditions. In addition, Khatir et al. [1] combined the CFD model of the oven with a multi-objective terms of energy consumption, conventional bread baking with baking performed under short infrared emitters (IR). Authors ensure the same kinetics of crust development and quality criterion maintaining baking time and lowering oven temperature for IR baking.

68 IR technology allowed reducing $20 \%$ of the total energy consumption.

69 It is noticeable that all the mentioned works focused on energy management during bread baking being difficult to find precedents on other kind of bakery product. In consequence the aim of this article is to estimate energy requirements during sponge

72 cake baking. For this goal, oven energy consumption was calculated and both 
experimental and modeling approaches were performed to calculate the product energy demand. Additionally, the process efficiency was evaluated relating the oven energy consumption and the product energy demand.

\section{Materials and Methods}

\subsection{Experimental baking tests}

For this study two batch-type electric ovens were used (Figure 1): a domestic oven (Ariston FM87-FC, Italy), and a semi-industrial convective oven (Multiequip HCE3/300, Argentine). The first one was used for natural convection (NC) baking tests (with the upper and lower resistances on) while the second one has the heating resistance and a fan installed on the back wall, which propelled the air at $2.8 \mathrm{~m} / \mathrm{s}$ (fixed air velocity) allowing to operate under forced convection mode (FC). Also, this equipment enables to perform steam-assisted forced convection mode (SFC). A connection pipe allows water input into the chamber, which evaporates instantaneously; each test consumed approximately $600 \mathrm{ml}$ of water to generate steam. For all the tests, the samples were placed over a tray, in the middle of the oven chambers.

The nominal oven temperature was set at 140,160 and $180{ }^{\circ} \mathrm{C}$ for the three different baking modes (9 total baking conditions). The oven was preheated until it reached the pre-set temperature before every test. Table 1 shows the experimental characteristics and the labels used to reference each condition. The measurement of effective temperature $\left(T_{\text {eff }}\right)$ is detailed in [9]. Additional experiments were performed to characterize both ovens in permanent mode at high temperature (nominal temperature equal to $185^{\circ} \mathrm{C}$ ), without samples inside the oven. In these cases $T_{\text {eff }}$ were higher than the one obtained with the baking sample, being 206 and $196{ }^{\circ} \mathrm{C}$ for $\mathrm{NC}$ and $\mathrm{FC}$ modes. 
Sponge cake batter was made mixing $270 \mathrm{~g}$ whole fresh eggs for $2 \mathrm{~min}$ at a $240 \mathrm{rpm}$ in a

97 multifunction food processor (Rowenta Universo 700, France), then adding $360 \mathrm{~g}$ dry premix, Satin Cake Premix (Puratos, Argentine) and mixing 2 min more. The batter composition resulted: $45.6 \%$ carbohydrates, $9.4 \%$ proteins, $9.0 \%$ fat, and $36.0 \%$ water. Finally $500 \mathrm{~g}$ of batter were dosed in an aluminium cake pan $(18 \mathrm{~cm}$ diameter, 7 $\mathrm{cm}$ height), which gives an initial batter height of $2.5 \mathrm{~cm}$.

102

103
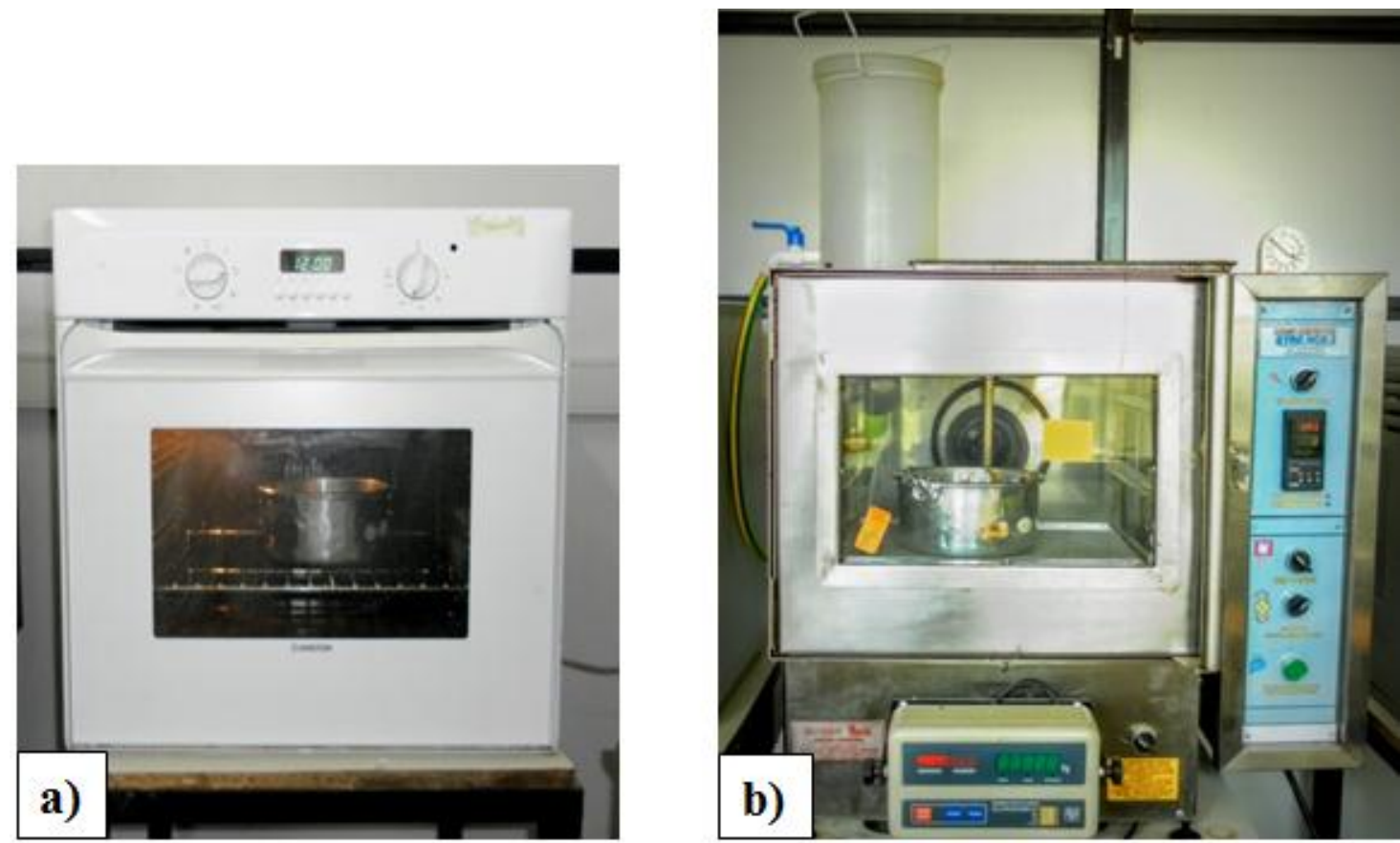

Figure 1. Ovens used for the baking experiences a) domestic oven and b) semiindustrial convective oven.

For sample and oven temperatures recording, T-type thermocouples (Omega, USA) connected to a data logger (Keithley DASTC, USA), were used. Cake temperature profile was obtained from three thermocouples fixed to the pan before filling it with the batter (without interfering with cake development). Their positions were carefully selected according to previous published results to ensure that the coldest region inside the product was monitored. Thus, two of them were positioned in the axial axis of the 
113 sample $(r=0)$ at $7.5 \mathrm{~cm}(T 1)$ and at $5.5 \mathrm{~cm}(T 2)$ from the pan bottom (being outside the

114 sample at the beginning of the process and covered while expansion occurred). The

115 third one (T3) was positioned near the pan wall $(r=7.5 \mathrm{~cm}), 2 \mathrm{~cm}$ from its bottom

116 (inside the sample during the whole experiment). On the other hand, oven temperature

117 ( $T_{\text {oven }},{ }^{\circ} \mathrm{C}$ ) was recorded by placing two thermocouples in the middle of the oven

118 chamber, near the sample. Two replicates were performed for each baking condition.

Table 1. Experimental conditions of the baking tests.

\begin{tabular}{|c|c|c|c|}
\hline & \multicolumn{3}{|c|}{ Set temperature $\left({ }^{\circ} \mathrm{C}\right)$} \\
\hline & 140 & 160 & 180 \\
\hline & \multicolumn{3}{|c|}{ Natural convection } \\
\hline & NC1 & NC2 & NC3 \\
\hline $\mathrm{T}_{\text {eff }}\left({ }^{\circ} \mathrm{C}\right)$ & $145.4 \pm 4.5$ & $161.4 \pm 4.7$ & $185.8 \pm 4.1$ \\
\hline \multirow[t]{3}{*}{$\mathrm{t}_{\mathrm{b}}(\min )$} & $51.4 \pm 0.3$ & $42.6 \pm 1.2$ & $32.3 \pm 1.6$ \\
\hline & \multicolumn{3}{|c|}{ Forced convection } \\
\hline & FC1 & FC2 & FC3 \\
\hline $\mathrm{T}_{\mathrm{eff}}\left({ }^{\circ} \mathrm{C}\right)$ & $150.2 \pm 6.9$ & $175.6 \pm 4.9$ & $194.0 \pm 5.5$ \\
\hline \multirow[t]{3}{*}{$\mathrm{t}_{\mathrm{b}}(\min )$} & $40.3 \pm 0.6$ & $32.1 \pm 0.8$ & $29.7 \pm 1.0$ \\
\hline & \multicolumn{3}{|c|}{ Steam assisted forced convection } \\
\hline & SFC1 & SFC2 & SFC3 \\
\hline $\mathrm{T}_{\text {eff }}\left({ }^{\circ} \mathrm{C}\right)$ & $151.2 \pm 6.3$ & $166.2 \pm 6.1$ & $183.5 \pm 6.7$ \\
\hline $\mathrm{t}_{\mathrm{b}}(\min )$ & $40.0 \pm 0.5$ & $31.8 \pm 1.2$ & $28.0 \pm 0.4$ \\
\hline
\end{tabular}

121

122 The baking time, defined as the instant when the minimal internal temperature reaches $12395{ }^{\circ} \mathrm{C}$ [9], is also informed in Table 1 . In spite of the wide range of baking times

124 detailed in Table 1, the thorough analysis of the quality characteristics of the baked 125 sponge cakes indicates that the colour kinetic parameters strongly depends on the 126 baking condition. However, the final crust colour, measured by a browning index, was 127 always in the range [100 - 110]. Additionally, no significant differences among baking 128 conditions in crust thickness or crumb structure were found [10]. To account for the 129 process yield, the sample weight was monitored during the whole process. Then, the 
130 weight loss $(W L(t))$ was calculated as a function of the initial cake weight $\left(m_{0}\right)$ and the

131 weight at time $t(m(t))$ :

$$
W L(t)=\frac{m_{0}-m(t)}{m_{0}} 100
$$

\subsection{Oven energy consumption}

136 The oven energy consumption depends on the electrical resistances heating power

$137\left(N_{p, \text { heat }}\right)$, the fan power $\left(N_{p, f a n}\right.$, only in FC and SFC modes $)$ and the effective heating time

$138[11,12]$. Both ovens used in this work have an ON/OFF control system, that is the

139 heating resistances were turned on if the oven temperature was lower than the set value,

140 when the set temperature was reached the heating resistances turned off and energy

141 consumption stopped, and so on. Thus, the oven energy consumption was intermittent.

142 Therefore, the specific oven energy consumption (OEC) was expressed according to Eq.

$$
O E C=\frac{1}{m_{0}}\left(N_{p, \text { heat }} f+N_{p, f a n}\right) t_{b}
$$

$147 N_{p, \text { heat }}$ was measured with the oven empty working at the maximum temperature, using a

148 clamp tester (SEW ST-300, Taiwan), values of 1.98 and $1.8 \mathrm{~kW}$ were obtained for

149 Ariston and Multiequip ovens, respectively. The fan power was much lower than the

150 heating one $(0.05 \mathrm{~kW})$, notwithstanding this contribution was considered in the

151 estimation of $O E C$.

152 On the other hand, the usage factor $f$, which represents the effective heating time, 153 depends on cooking temperature and on the product load. In the present work the 
154 product load was the same in all the experimental tests, thus the $f$ value only depends on

155 oven temperature and was calculated as the ratio between the total heating time and the

156 baking time $t_{b}$. The total heating time was estimated from the oven temperature profile,

157 adding all the periods with increasing oven temperature. The usage factor of the empty

158 oven in permanent mode and high temperature was 0.46 and 0.47 for NC and FC ovens,

159 respectively.

160 Once the oven energy consumption was calculated, the baking specific energy cost 161 (SEC) was estimated on the basis of 160 working hours per month. Both variable and

162 fixed costs were taken into account (reference price from the local energy distribution 163 company [13]). The monthly fixed cost (medium commercial use) was $27.7 \$ /$ month, 164 and the variable one was $0.042 \$ / \mathrm{kWh}$.

\subsection{Experimental product energy demand}

167 In the present study the experimental specific product energy demand $\left(P E D_{\text {exp }}\right)$ was 168 defined considering sensible and latent heat contributions, assuming that water is the 169 only component that evaporates during sponge cake baking, the latent heat can be 170 expressed in function of the enthalpy of water vaporization $\left(\lambda, 2257 \times 10^{3} \mathrm{~J} \mathrm{~kg}^{-1}\right)$ and the 171 amount of evaporated water:

$$
P E D_{\text {exp }}(t)=\frac{m_{0} C p_{\text {sen }}\left(T_{\text {ave }}(t)-T_{0}\right)+\lambda\left(m_{0}-m(t)\right)}{m_{0}}
$$

175 In order to evaluate the sensible specific heat (Eq. (8) detailed later), Choi \& Okos [14]

176 approach was employed with an average temperature $T_{a v e}(t)$, estimated from the 177 experimental ones (T1, T2 and $T 3)$. 
178 As it can be seen the difference between Eq. (2) (OEC) and Eq. $3\left(P E D_{\text {exp }}\right)$ comprises

179 the energy needed to heat the oven components (walls, tray, etc.) and mainly the heat

180 loss through the oven walls to the ambient.

181 The efficiency of the process $(\eta)$ is defined as the ratio of the energy demand of the

182 product to the energy consumption of the equipment [5], with $P E D_{\exp }$ calculated at the 183 baking time $t_{b}$.

184

$$
\eta=100 \frac{P E D_{\text {exp }}}{O E C}
$$

\subsection{Simulated product energy demand}

188 Usually, there can be found in the literature many mathematical models that describe the baking process in terms of energy conservation laws $[15,16]$; only a few of them have the intrinsic capacity to predict the product energy demand $[1,7]$.

191 In the present study, a mathematical model previously developed for sponge cake

192 baking [9] was used to estimate the product energy demand. This model comprises

193 product expansion considering the simulation domain $(\Omega)$ as a continuous and

194 homogeneous geometry that expands [9]. The energy balance in this domain is 195 expressed as follows:

196

$$
\rho C p_{\text {app }} \frac{\partial T}{\partial t}=\nabla(k \nabla T), \forall \Omega
$$

199 Water evaporation is considered through the thermal properties. Global density (Eq. (6))

200 was expressed according to Baik et al.[17]; the apparent specific heat (Eq. (7)) 
202 (Eq. (10)) was evaluated with Rask [19] expression.

$$
\rho= \begin{cases}1013-6.13 T & T<100 \\ 400 & T \geq 100\end{cases}
$$

210 In Eq. (8) the components are water, carbohydrates, proteins, fat and ashes, being

$211 C \mathrm{p}_{\text {water }}=4180 ; \mathrm{C} \mathrm{p}_{\mathrm{CH}}=1547 ; \mathrm{C} \mathrm{p}_{\text {prot }}=1711 ; \mathrm{Cp}_{\text {fat }}=1928 ; \mathrm{Cp}_{\text {ash }}=908$. In Eq. (9) $\mathrm{m}_{\text {water }}$

212 represents the total mass of water evaporated during baking and $\Delta \mathrm{T}$ is the temperature

213 interval of this phase change $\left(5^{\circ} \mathrm{C}\right)$.

214 Particularly in the numerical simulation, the domain was defined as the half cross-

215 sectional area of the cake using axisymmetric 2D geometry. Regarding the boundary 216 conditions of the energy balance (Eq. (5)), axial symmetry was considered in $(r=0)$.

217 Besides, convective heat transfer at the cake top, and mould bottom and wall was 218 assumed, using an effective heat transfer coefficient $\left(h_{c}\right)$ (Eq. (11)):

219

$$
k \nabla T=h_{c}\left(T_{e f f}-T\right)
$$


222 The effective heat transfer coefficient was measured with a heat flux sensor (Omega

223 HFS4, USA) considering an average value of $h_{c}$ for the entire sample surface, being 15 ,

22425 and 20 for NC, FC and SFC baking modes, respectively [9].

225 To take into account the product expansion, mesh deformation was applied assigning a

226 prescribed displacement velocity to the top surface of the cake, being this parameter

227 derived from experimental height evolution data analysis [9].

228 The prediction of the specific product energy demand $\left(P E D_{\text {sim }}\right)$ was coupled to the baking model. Thus, the simulated product energy demand at a given time can be expressed in terms of the local energy in the whole domain:

$$
P E D_{\text {sim }}(t)=\frac{1}{m_{0}} \int_{0}^{t}\left(\int_{\Omega} \rho C p \frac{\partial T}{\partial t} d \Omega\right) d t
$$

233 The baking model was solved with the finite element method using COMSOL

234 Multiphysics 3.5 coupled with MATLAB 7.8.0 [9].

235 Finally, the model prediction accuracy was assessed by the average absolute relative error $(\varepsilon)$ between the experimental and predicted specific product energy demand:

$$
\varepsilon=\frac{100}{n} \sum_{i=1}^{n}\left(\frac{\left|P E D_{\text {exp }}-P E D_{\text {sim }}\right|}{P E D_{\text {exp }}}\right)_{i}
$$

\section{Results and Discussion}

\subsection{Oven performance}

242 In order to determine the energy consumption during the process it is essential to study 243 and describe the oven performance. In this sense, oven temperature recordings during 
24427 minutes are shown in Figure 2a. Only three of the nine tested conditions are shown,

245 one of each convection mode. In general their evolution was quite repetitive (different 246 oven temperature, same convection mode). All conditions showed an oscillatory

247 behaviour, typical of an ON/OFF control system as described in Section 2.2.

a)

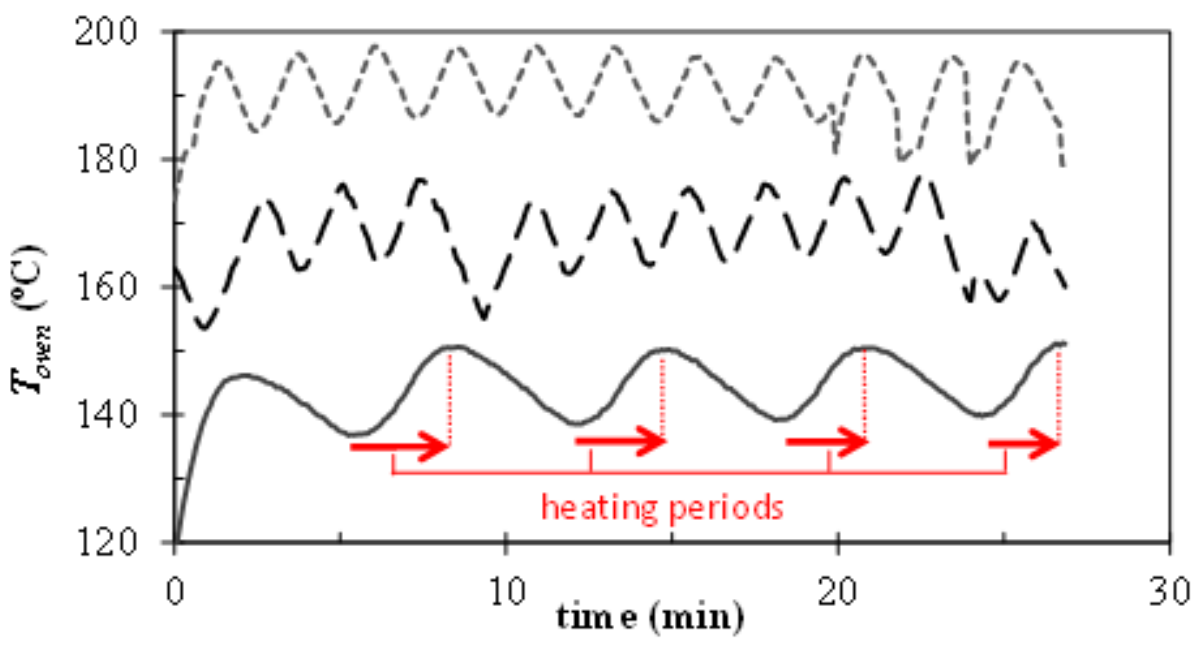

b)

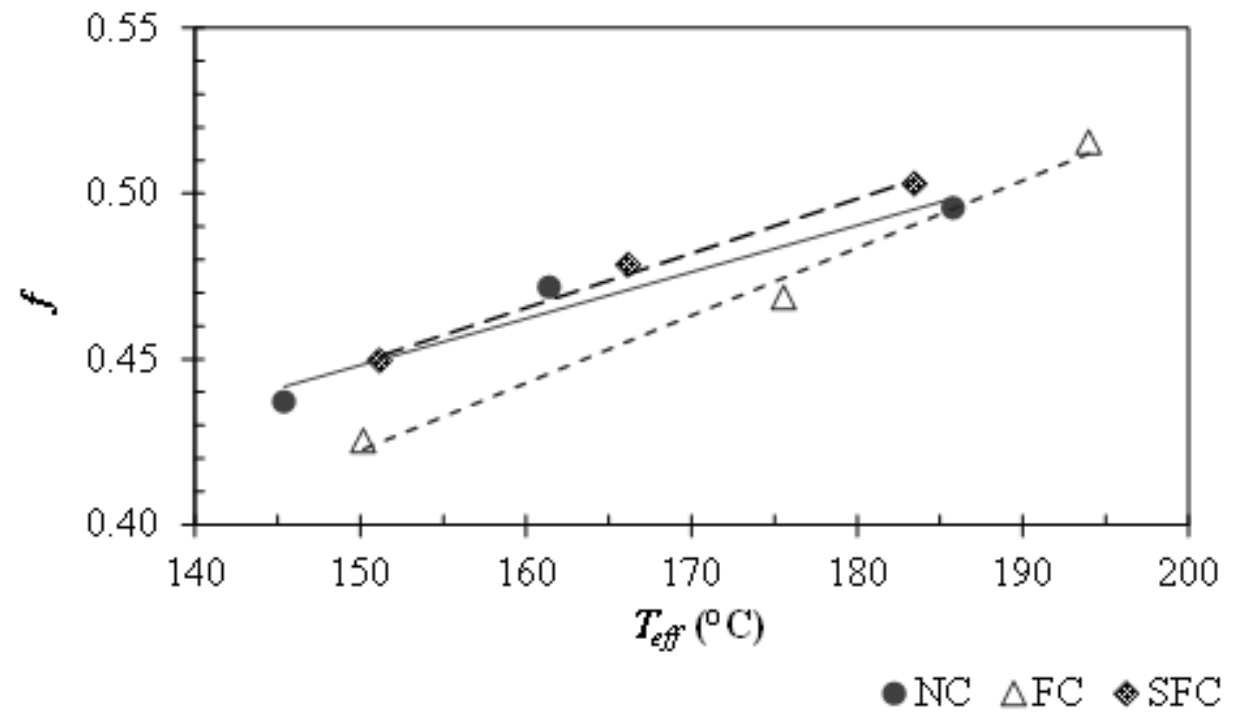

Figure 2. a) Experimental oven temperature $\left(T_{\text {oven }},{ }^{\circ} \mathrm{C}\right)$ recordings of some baking conditions and b) usage factor $(f)$ values vs. effective temperature $\left(T_{\text {eff }},{ }^{\circ} \mathrm{C}\right)$ for each convection mode. 
254 In the case of natural convection mode, there was observed a regular wave with smaller amplitude than the other two modes. Forced convection mode also presented a regular variation with a shorter period wave. On the contrary, vapour injection produced a nonregular oscillation making more difficult the temperature control. Therefore, each condition was characterized with an effective temperature as it was informed in Table 1.

259 Also, in Figure 2a the intervals of time where the oven temperature increases are highlighted in order to obtain the total heating time to calculate the $f$ factor. This way, with oven temperature profile and baking times informed in Table $1, f$ was calculated. Figure $2 \mathrm{~b}$ shows these values as a function of $T_{\text {eff }}$ for each baking mode. It is evident that $f$ increases with oven temperature, while there is not a clear dependence with the convection mode. Thus, a higher operative temperature requires longer effective heating times during the baking test, no matter the convection mode.

266 Calculated $O E C$ values are presented in Table 2, these results are in the same range 267 reported by [5], in particular the authors informed an average value of $5.34 \mathrm{MJ} / \mathrm{kg}$ of 268 bread considering fourteen electrical ovens. Also these values are comparable to the 269 ones presented by [20] who measured the specific energy consumption in an industrial 270 bakery, considering only the percentage of energy used in the baking process, the 271 authors reported $1.27 \mathrm{kWh} / \mathrm{kg}$ processed flour for products baked in electrical oven, the 272 average value of our results is 1.86 in the same basis. It was found that higher operative 273 temperature favours energy savings and in addition, when comparing between 274 convection modes, NC requires higher energy than the other modes. Even though $f$ increases with oven temperature, smaller baking times are associated with higher oven temperatures which lead to lower energy consumption. 
Table 2. Experimental variables calculated from Eqs. (1), (3), (4) and (5).

\begin{tabular}{cccccccccc}
\hline & NC1 & NC2 & NC3 & FC1 & FC2 & FC3 & SFC1 & SFC2 & SFC3 \\
\hline $\begin{array}{c}O E C \\
\left(\mathrm{~kJ} \mathrm{~kg}^{-1}\right)\end{array}$ & 5340.4 & 4772.2 & 3801.2 & 3947.1 & 3439.7 & 3481.5 & 4123.4 & 3481.0 & 3209.3 \\
$\begin{array}{c}S E C \\
\left(\$ \mathrm{~kg}^{-1}\right)\end{array}$ & 0.250 & 0.242 & 0.228 & 0.230 & 0.222 & 0.223 & 0.232 & 0.223 & 0.219 \\
$W L(\%)$ & 5.7 & 5.2 & 4.9 & 6.9 & 7.2 & 7.4 & 6.6 & 6.5 & 6.4 \\
$P E D$ & 347.0 & 364.2 & 331.0 & 399.0 & 428.8 & 453.9 & 362.2 & 356.8 & 370.4 \\
$\left(\mathrm{~kJ} \mathrm{~kg}^{-1}\right)$ & \pm 1.7 & \pm 3.0 & \pm 9.4 & \pm 4.1 & \pm 4.0 & \pm 0.6 & \pm 0.6 & \pm 3.5 & \pm 1.0 \\
$\eta(\%)$ & 6.5 & 7.7 & 8.7 & 10.1 & 12.5 & 13.0 & 8.8 & 10.2 & 11.5 \\
\hline
\end{tabular}

280

281 To complete the analysis, Figure 3 presents $O E C$ vs. $T_{\text {eff }}$ for each baking condition. This

282 confirms the behaviour mentioned above and also shows that FC and SFC modes follow

283 the same trend with the exception of the lowest oven temperature. In fact, steam

284 addition is reflected in a decrease of the effective temperature.

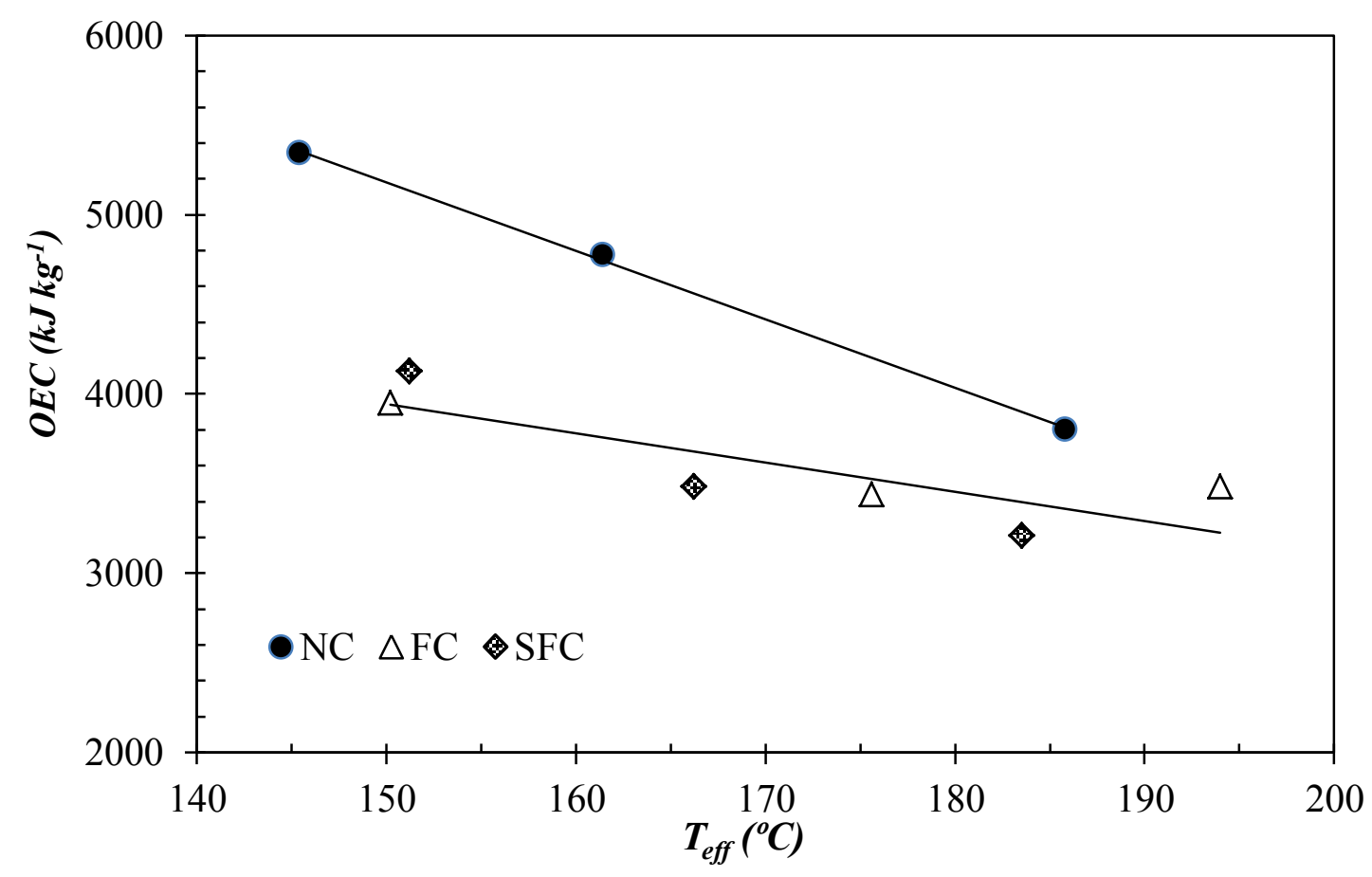

286 Figure 3. Specific oven energy consumption $\left(O E C, \mathrm{~kJ} \mathrm{~kg}^{-1}\right)$ measured at the end of baking for each baking condition. 
289 Also the specific energy cost is reported in Table 2. As it was expected, SEC presents

290 the same trend that $O E C$, with a difference of $14 \%$ between the maximum and

291 minimum energy consumption conditions (NC1 and SFC3 respectively).

292

293

\subsection{Product energy demand}

294 As stated before, the amount of water that evaporates during the process strongly affects

295 the energy demand. In this sense, sponge cake weight loss was monitored during the 296 baking tests and the results are shown in Figure 4. First of all, the rate of $W L$ evolution

297 significantly increases when baking at the highest oven temperature for the three 298 convection modes. Nevertheless, there were not significant differences between $W L$ 299 values at the end of baking in the same convection mode (Table 2), because of the

300 combined effect of the $W L$ rate and the baking time. Secondly, when comparing 301 between convection modes it is noticeable that forced convection (Figures $4 \mathrm{~b}$ and $4 \mathrm{c}$ ) 302 induces a faster and higher weight loss compared with natural convection mode (Fig. 303 4a) and that steam injection reduces this effect. Moreover, to reinforce this idea, WL 304 values at the end of the process were $5.3 \pm 0.4,7.2 \pm 0.3$ and $6.5 \pm 0.8$, for NC, FC and 305 SFC modes, respectively. This is consistent with the results informed by other authors $306[8,15]$.

$307 P E D_{\text {exp }}$ was calculated at each step time that $W L$ was registered during the process. This 308 evolution is presented in Figure 5. There was observed that for all the baking conditions 309 this parameter increased with time and also that as baking evolves, the rate of change 310 slows down. What is more, higher oven temperature induces higher energy demand.

311 Table 2 details the $P E D_{\exp }$ calculated at the end of the process for each baking 312 condition. There was observed that $P E D_{\exp }$ is closely related to $W L$ behaviour. 

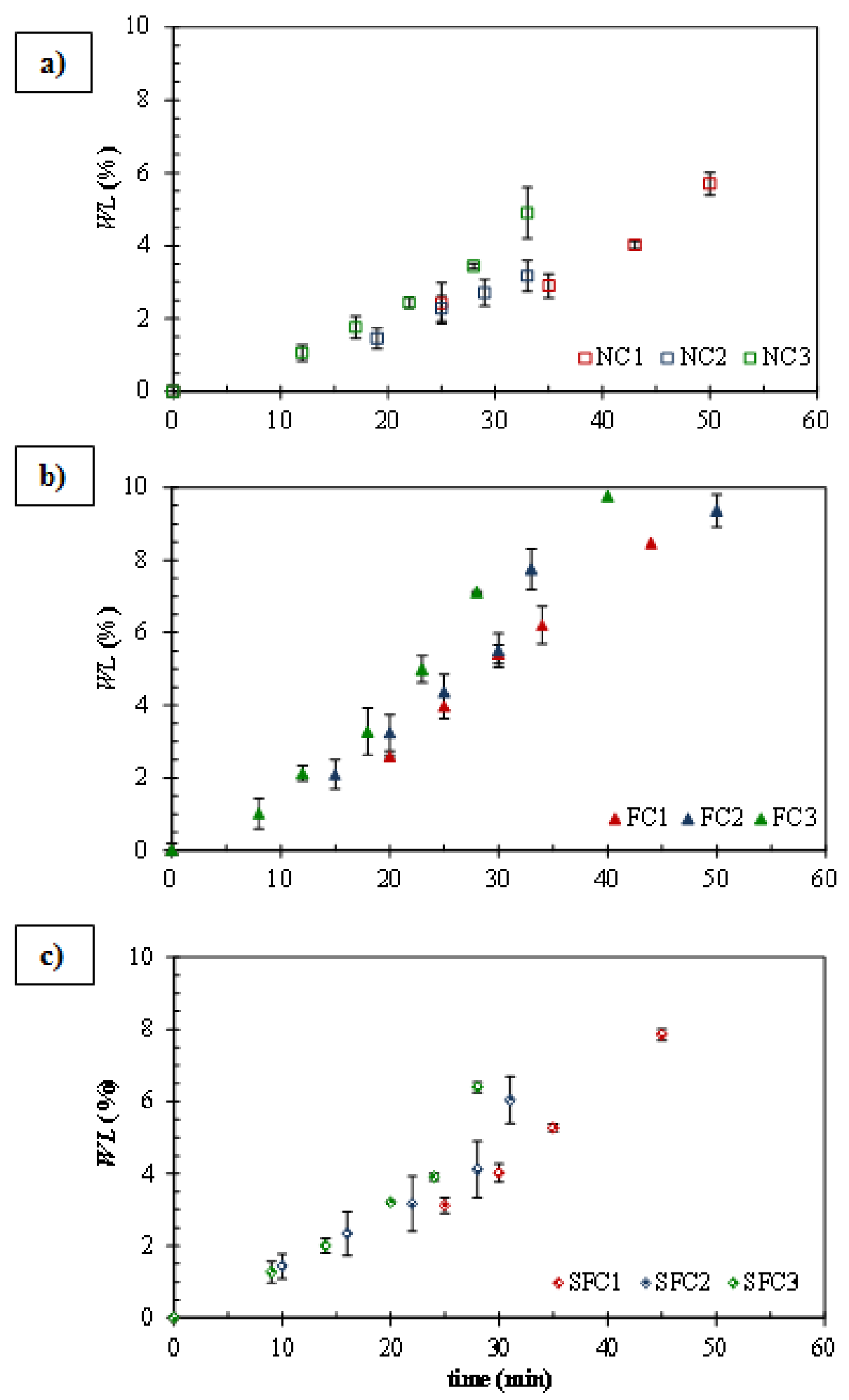

314

315 Figure 4. Weight loss ( $W L, \%)$ evolution during baking of sponge cake: a) natural 316 convection, b) forced convection and c) steam assisted forced convection mode. 

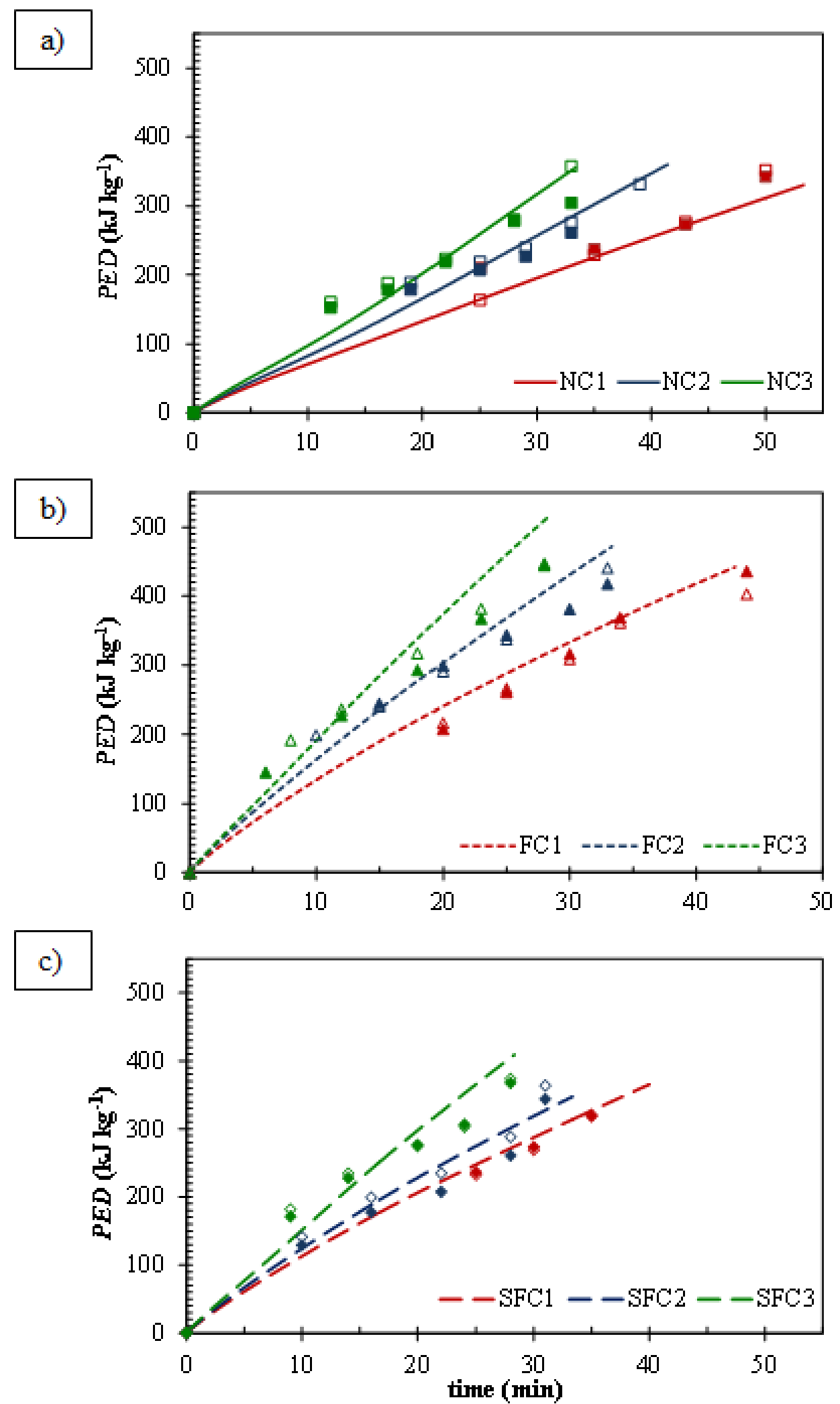

319 Figure 5. Specific product energy demand ( $\left.P E D, \mathrm{~kJ} \mathrm{~kg}^{-1}\right)$ during baking: experimental 320 measured values (empty and full symbols) and simulated values (full lines). 
322 Other researchers focused in this issue using a similar method to calculate energy

323 demand particularly for bread baking. In this sense, Paton et al. [7] informed similar

324 values considering the energy demand for heating the dough, the energy to evaporate 325 around $10 \%$ of the initial moisture content and the energy required for starch 326 gelatinization. Also, Ploteau et al. [8] estimated a similar energy demand taking into 327 account the main transformation that occurs during baking (dough into crumb and crust)

328 and water evaporation. Notice that, as was expected, the energy demand for bread 329 baking is higher than the one required for sponge cake, due to the higher level of 330 dehydration that this product suffers.

331 Besides, as stated in Section 2.4, $P E D_{\text {sim }}$ was coupled to the mathematical baking 332 model. In addition to $P E D_{\text {exp }}$, Figure 5 shows $P E D_{\text {sim }}$ values. In fact, the average error 333 (Eq. (13)) was 8.0, 10.1 and $8.0 \%$ for $\mathrm{NC}, \mathrm{FC}$ and SFC, respectively. The highest 334 relative error values were associated to the baking conditions with the highest effective temperature (NC3, FC2, FC3 and SFC3). From these results it is noticeable that the

336 model successfully reproduces the experimental behaviour discussed above, 337 demonstrating the ability of this mathematical model to incorporate product energy 338 demand.

\subsection{Efficiency of the process}

341 Once the $O E C$ and $P E D_{\text {exp }}$ were obtained, the energy efficiency of the process was

342 calculated as the ratio between these two variables (Eq. (4)). The results are presented in

343 Figure 6 as a function of $T_{\text {eff }}$ for each baking condition. In all cases $\eta$ increases linearly

344 with $T_{\text {eff, }}$ being more evident the effect of oven temperature in FC and SFC modes, even

345 though this last one presented lower efficiency due to the energy to produce steam 346 inside the oven chamber. Also from the values detailed in Table 2, the greatest 
347 efficiency corresponded to FC mode and the lowest to NC mode. This effect is mainly

348 explained by the higher heat and mass transfer rates associated to the forced convection

349 mode which reduces the baking time, in concordance with previous published results

$350[5,6]$. In addition, Paton et al. and Khatir et al. [7,21] who studied the optimization of

351 bread baking process, suggested that one way to achieve energy savings is to reduce the

352 baking time by improving the oven design.

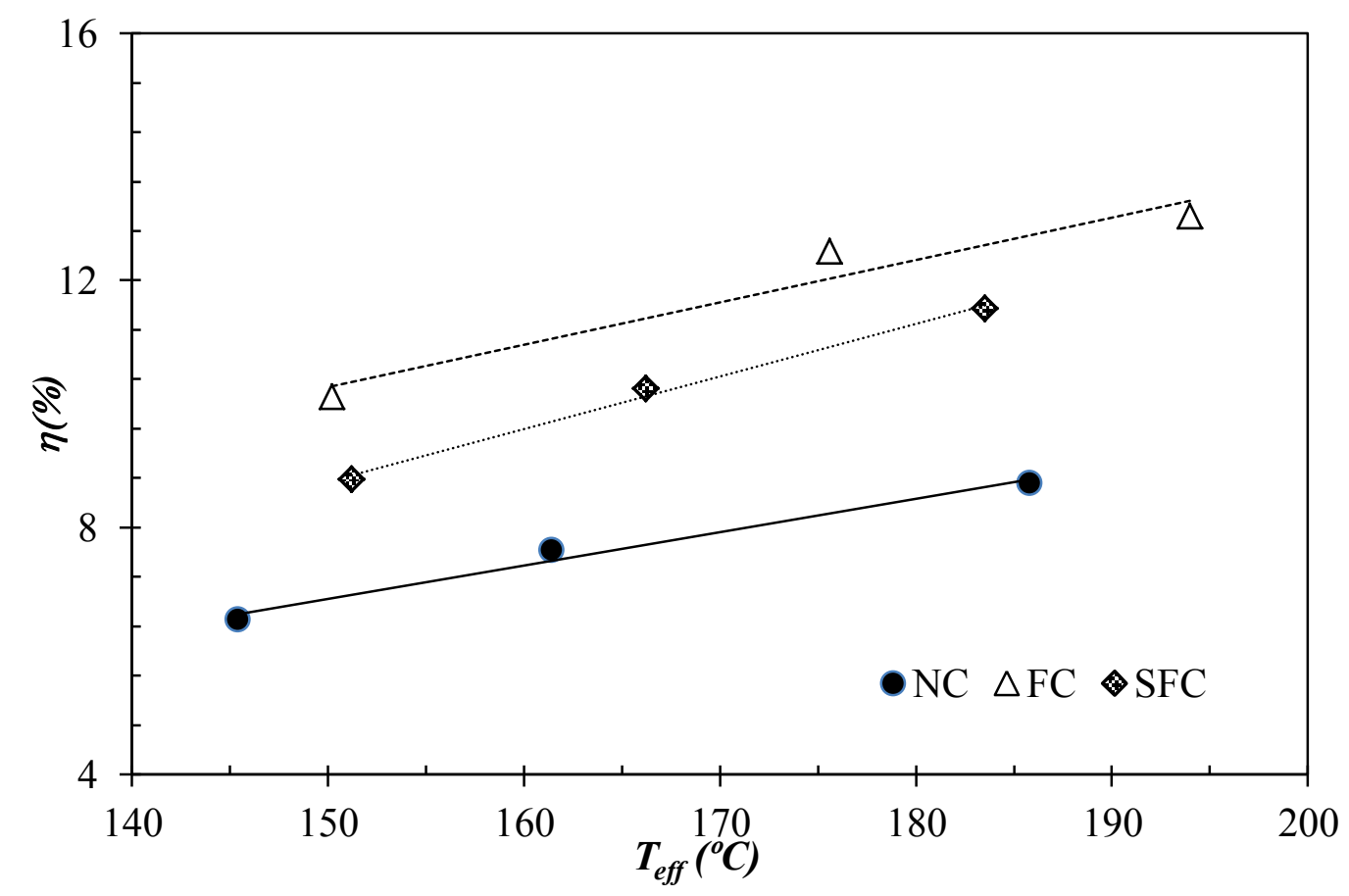

353

354 Figure 6. Process efficiency $(\eta, \%)$ vs. effective temperature $\left(T_{\text {eff, }}{ }^{\circ} \mathrm{C}\right)$ for each 355 convection mode.

\section{Conclusions}

357 In this work energy requirements during sponge cake baking were studied. The analysis

358 of the oven energy consumption indicated that higher oven temperatures and forced

359 convection favours energy savings, due to the decrease of the baking times. On the contrary, high oven temperature induces an increase of the product energy demand. This 
361 parameter is closely related to the weight loss, in consequence both present similar

362 trends. Additionally, the baking model successfully represented the product energy 363 demand evolution; in fact, the average error calculated between experimental and

364 simulated values was less than $10 \%$.

365 To take into account the economic aspects, the specific energy cost was estimated,

366 founding a difference of $14 \%$ between the minimal and maximum values.

367 Finally, a measure of the process efficiency was obtained, it increased linearly with the 368 effective temperature, and the greatest values corresponded to FC mode and the lowest 369 to NC mode, indicating again the influence of the reduction of the baking time.

370 In conclusion, on the basis of the results presented in this work, the better baking 371 condition was the fast one, FC3. Notwithstanding, complementary studies of the quality 372 characteristics of the baked sponge cakes (results not shown in this work), shown that 373 forced convection baking with high oven temperature was the condition with the lowest 374 appreciation by the potential consumers, indicating that the selection of an optimal 375 baking condition implies the joint analysis of diverse aspects.

377 Acknowledgments

378 Authors acknowledge Consejo Nacional de Investigaciones Científicas y Técnicas 379 (CONICET, PIP 0180), Agencia Nacional de Promoción Científica y Tecnológica 380 (ANPCyT PICT 2013-1637), and Universidad Nacional de La Plata (UNLP, I183) from 381 Argentina for their financial support.

\section{References}

383 [1] Z. Khatir, J. Paton, H. Thompson, N. Kapur, V. Toropov, Optimisation of the 
energy efficiency of bread-baking ovens using a combined experimental and computational approach, Applied Energy 112 (2013) 918-927.

[2] P. Therkelsen, E. Masanet, E. Worrell, Energy efficiency opportunities in the U.S. commercial baking industry, Journal of Food Engineering 130 (2014) 1422.

[3] A. Mondal, A.K. Datta, Bread baking - A review, Journal of Food Engineering 86 (2008) 465-474.

[4] S.M. Goñi, V.O. Salvadori, Energy consumption estimation during oven cooking of food., in: S. Reiter (Ed.), Energy Consumption (2014) pp. 99-116.

[5] A. Le-bail, T. Dessev, V. Jury, R. Zuniga, T. Park, M. Pitroff, Energy demand for selected bread making processes: Conventional versus part baked frozen technologies, Journal of Food Engineering 96 (2010) 510-519.

[6] M. Alamir, E. Witrant, G. Della Valle, O. Rouaud, C. Josset, L. Boillereaux, Estimation of energy saving thanks to a reduced-model-based approach: Example of bread baking by jet impingement, Energy 53 (2013) 74-82.

[7] J. Paton, Z. Khatir, H. Thompson, N. Kapur, V. Toropov, Thermal energy management in the bread baking industry using a system modelling approach, Applied Thermal Engineering 53 (2013) 340-347.

[8] J.P. Ploteau, P. Glouannec, V. Nicolas, A. Magueresse, Experimental investigation of French bread baking under conventional conditions or short infrared emitters, Applied Thermal Engineering 75 (2015) 461-467.

[9] M.M. Ureta, D.F. Olivera, V.O. Salvadori, Baking of Sponge Cake: Experimental characterization and mathematical modelling, Food and Bioprocess Technology 9 (2015) 664-674.

[10] M.M. Ureta, D.F. Olivera, V.O. Salvadori, Influence of baking conditions on the 
quality attributes of sponge cake, Food Science and Technology International Online version (2016). doi:10.1177/1082013216666618.

411 [11] S.M. Goñi, V.O. Salvadori, Model-based multi-objective optimization of beef roasting, Journal of Food Engineering 111 (2012) 92-101.

[12] M.A. Townsend, S. Gupta, The roast: Nonlinear modeling and simulation, Journal of Food Process Engineering 11 (1988) 17-42.

[13] Edelap, Cuadros Tarifarios, (2016). https://oficinavirtual.edelap.com.ar/reports/Cuadro_Tarifario_de_Publicacion_02 .16.pdf. Last accesed September 15, 2016.

[14] Y. Choi, M.R. Okos, Effects of temperature and composition on the thermal, properties of foods, Food Engineering and Process Applications. Elsevier Applied Science Publishers (1986) pp: 93-101.

[15] M. Sakin, F. Kaymak-ertekin, C. Ilicali, Modeling the moisture transfer during baking of white cake, Journal of Food Engineering 80 (2007) 822-831.

[16] M.S. Andresen, Experimentally supported mathematical modeling of continuous baking processes, (2013) PhD Thesis, Division of Industrial Food Research, National Food Institute, Technical University of Denmark, Lyngby, Denmark.

[17] O.D. Baik, S.S. Sablani, M. Marcotte, F. Castaigne, Modeling the thermal properties of a cup cake during baking, Journal of Food Science 64 (1999) 295299.

[18] C. Bonacina, G. Comini, A. Fasano, M. Primicerio, Numerical solution of phasechange problems, International Journal of Heat and Mass Transfer 16 (1973) 1825-1832.

[19] C. Rask, Thermal properties of dough and bakery products: A review of published data, Journal of Food Engineering 9 (1989) 167-193. 
434 [20] R. Kannan, W. Boie, Energy management practices in SME - case study of a 435 bakery in Germany, Energy Conversion and Management 44 (2003) 945-959.

436 [21] Z. Khatir, A.R. Taherkhani, J. Paton, H. Thompson, N. Kapur, V. Toropov, 437 Energy thermal management in commercial bread-baking using a multi-objective optimisation framework, Applied Thermal Engineering 80 (2015) 141-149.

439

440 